\title{
SISTEM PENDUKUNG KEPUTUSAN CALON PENERIMA BANTUAN PROGRAM KELUARGA HARAPAN (PKH) MENGGUNAKAN METODE ANALYTICAL HIERARCY PROCESS (AHP)
}

\author{
Bambang Suprapto ${ }^{1}$ Ahmad Sujoni ${ }^{2}$ \\ Magister Teknik Informatika ${ }^{1}$ Sistem Informasi ${ }^{2}$ \\ AMIK Dian Cipta Cendikia Pringsewu ${ }^{12}$ \\ Jl. Ahmad Yani, No.134 Sidoharjo - Pringsewu, Lampung \\ E-Mail : supraptobambang88@gmail.com, sujonya@gmail.com
}

\begin{abstract}
ABSTRAK
Kemiskinan merupakan masalah kompleks yang bisa disebabkan dari berbagai faktor seperti : aspek ekonomi, sosiologis, antropologis, kebijakan, teknologi serta perubahan global. Kemiskinan juga berimplikasi terhadap pendidikan, kesehatan, kemampuan ekonomi, serta partisipasi masyarakat dalam sebuah negara. Di Indonesia Program Keluarga Harapan atau yang biasa disebut dengan PKH hadir sebagi salah satu solusi bagi negara untuk hadir membantu masyarakat miskin dan menjadi salah satu tahapan menuju sistem perlindungan sosial. Menurut Dinas Kementrian Sosial, Program Keluarga Harapan (PKH) adalah program pemberian bantuan bersyarat kepada Keluarga Miskin (KM) yang ditetapkan sebagai keluarga penerima manfaat (PKH). Dalam istilah internasional dikenal dengan Conditional Cash Transfers (CCT).
\end{abstract}

Untuk membantu pendamping PKH dalam mengolah data dalam proses seleksi penerima bantuan program keuarga harapan maka peneliti menggunakan metode Analytical Hierarcy Process (AHP) yang akan dihitung dengan menggunakan program aplikasi Microsoft Excel 2010 dan akan di input ke aplikasi web programing untuk memudahkan dalam penghitunganya.

Penentuan Kriteria Meliputi 9 Kriteria yang masing-masing kriteria memiliki 3 subkriteria yaitu : Kepemilikan Telfon Seluler, Pekerjaan, Penghasilan, Status Tempat Tinggal, Jenis Lantai, Kondisi Rumah, Fasilitas Jamban, Pendidikan, Wawancara Tetangga. Dari hasil penelitian ini diharapkan akan dapat membantu dan memudahkan pendamping PKH dalam proses seleksi penerima bantuan program keluarga harapan di Kabupaten Pesawaran Provinsi Lampung.

Kata kunci : Sistem Pendukung Keputusan, AHP, Program Keluarga Harapan (PKH), Microsoft Excel 2010, Web Programing, Kabupaten Pesawaran.

\section{ABSTRACT}

Poverty is a complex problem that can be caused by various factors such as: economic factors, sociological factors, anthropological factors, policy, technology and global changes. Poverty also has implications for education, health, economic capacity, and community participation in a country. In Indonesia the Indonesian Conditional Cash Transfer Program or commonly referred to as PKH is present as one of the solutions for the state to be present to help the poor and become one of the stages towards a social protection system. According to the Ministry of Social Affairs, Program Keluarga Harapan (PKH) is a conditional assistance program for Poor Families (KM) which is designated as a beneficiary family (PKH). In international terms it is known as Conditional Cash Transfers (CCT).

To assist the PKH companion in processing the data in the process of selecting recipients of the Program Keluarga Harapan, the researcher used the Analytical Hierarchy Process (AHP) method which will be calculated using the Microsoft Excel 2010 application program and will be input into the web programing application to facilitate the calculation.

The determination of the criteria included 9 criteria, each criterion has 3 sub-criteria, namely: Cellphone Ownership, Work, Income, Residence Status, Floor Type, House Condition, Latrine Facilities, Education, Neighbor Interviews. The result of this study was expected to be able to assist and facilitate the PKH 
companion in the process of selecting recipients of the Program Keluarga Harapan assistance in Pesawaran Regency, Lampung Province.

Keywords: Decision Support System, AHP, Program Keluarga Harapan (PKH), Microsoft Excel 2010, Web Programing, Pesawaran District.

\section{PENDAHULUAN}

Diberbagai negara dibelahan dunia, kemiskinan adalah salah satu hal yang paling penting untuk diperbincangkan, karena kemiskinan seringkali menjadi hambatan dalam proses pembangunan sebuah negara. Badan Pusat Statistik (BPS) mencatat, pada bulan September 2017 jumlah penduduk miskin, yakni penduduk dengan pengeluaran perkapita perbulan dibawah garis kemiskinan di Indonesia mencapai 26,58 juta orang $(10,12 \%)$ berkurang 1,19 juta orang dibandingkan dengan kondisi maret 2017 yang sebesar 27,77 juta orang $(10,64 \%)$. (Sumber : Berita Resmi Statistik Website : www.bps.go.id) Itu menandakan bahwa masih banyak penduduk miskin di Indonesia dan secara otomatis itu menjadi Pekerjaan Rumah bagi pemerintah untuk bagaimana menangani kemiskinan tersebut. [1]

Tabel 1.1 Perkembangan Tingkat Kemiskinan Sembilan Tahun Terakhir

Jumlah dan Persentase Penduduk Miskin, 1999-2017

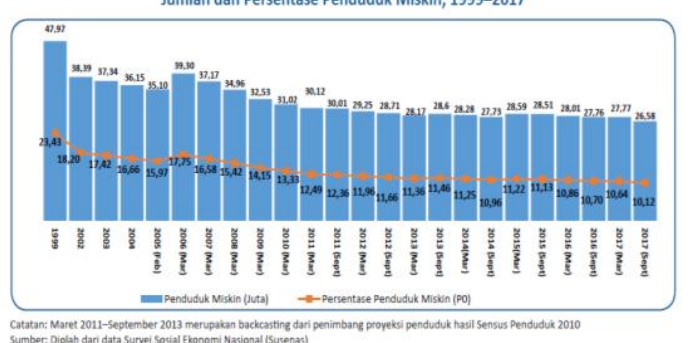

(sumber: Profil Kemiskinan di Indonesia September 2017)

Di Indonesia, sebagai upaya penanggulangan kemiskinan maka pemerintah Indonesia sejak tahun 2007 telah melaksanakan Program Bantuan Langsung Tunai Bersyarat (BLTB), yang dikenal dengan nama Program Keluarga Harapan (PKH) sebagai salah satu tahapan menuju sistem perlindungan sosial. Menurut Dinas Kementrian Sosial, Program Keluarga Harapan (PKH) adalah program pemberian bantuan bersyarat kepada Keluarga Miskin (KM) yang ditetapkan sebagai keluarga penerima manfaat (PKH). Dalam istilah internasional dikenal dengan Conditional Cash Transfers (CCT). [2]
Sedangkan Badan Pusat Statistik (BPS) Kabupaten Pesawaran mencatat, pada bulan Agustus 2017 jumlah penduduk miskin $(17,31 \%)$ atau sebesar 7.445.000 [3]

Tabel Garis Kemiskinan Kabupaten Pesawaran sebagai berikut :

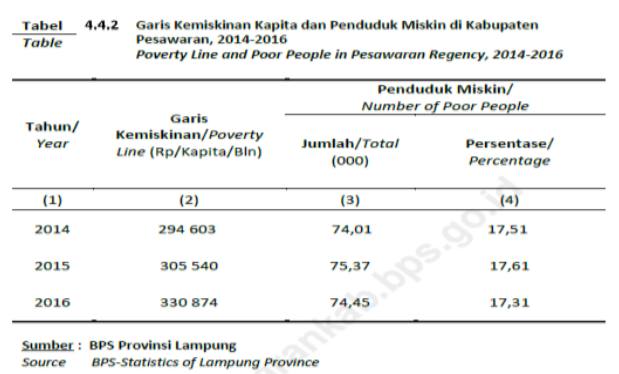

Berdasarkan wawancara yang dilakukan dengan Yuliantoro, S.Pd. sebagai salah satu pendamping lapangan program $\mathrm{PKH}$ Kecamatan Negerikaton, Kabupaten Pesawaran, selama ini data yang digunakan PKH dari BPS tidak valid (data tidak sesuai dengan keadaan sebenarnya), sehingga menyebabkan keluarga miskin yang memenuhi kriteria penerima bantuan program PKH malah tidak mendapatkan bantuan, tetapi malah sebaliknya, warga yang menerima bantuan adalah bukan keluarga miskin.

Sebelum penelitian ini, telah dilakukan penelitian tentang penentuan penerima program keluarga harapan menggunakan metode Analytical Hierarcy Process (AHP). Dalam penelitian tersebut telah dilakukan pembuatan sistem penunjang keputusan penerima bantuan $\mathrm{PKH}$ di Desa Bangunrejo, Kecamatan Punduh Pidada Kabupaten Pesawaran.[4] Sedangkan dalam penelitian kali ini menggunakan metode Analytical Hierarcy Process (AHP) yang akan dihitung dengan menggunakan program aplikasi Microsoft Excel 2010 dan akan di input ke aplikasi web programing untuk memudahkan dalam penghitunganya.

Metode Analytical Hierarcy Process (AHP) digunakan untuk menentukan bobot prioritas kriteria pada perhitungan dengan memperhatikan konsistensi pada bobot. [5] 
Kemudian data penerima program bantuan PKH yang sudah didapatkan dari kementrian akan diolah kembali menggunakan web programing yang tentu saja sudah diuji kebenaranya dengan membandingkan dengan hasil perhitungan menggunakan microsoft excel 2010. Data yang dihasilkan akan dijadikan acuan dalam penentuan keputusan calon penerima PKH. Penentuan kali ini diharapkan akan mampu menghasilkan calon penerima PKH di Kabupaten Pesawaran sesuai dengan harapan, sehingga diharapkan penyaluran PKH akan lebih tepat sasaran.

\subsection{Identifikasi Masalah}

Berdasarkan uraian latar belakang masalah, maka peneliti membuat identifikasi masalah sebagai berikut :

a. Selama ini data yang digunakan PKH dari BPS tidak valid (data tidak sesuai dengan keadaan sebenarnya), sehingga menyebabkan penyaluran dana bantuan PKH tidak sesuai harapan

b. Melakukan pengujian menggunakan sistem pendukung keputusan calon penerima bantuan PKH menggunakan metode AHP

\subsection{Rumusan Masalah}

Berdasarkan latar belakang diatas, maka dirumuskan permasalahan yang akan didapatkan solusinya antara lain sebagai berikut :

a. Bagaimana cara untuk menentukan penerima bantuan PKH tersebut

b. Bagaimana menentukan sistem pendukung keputusan yang tepat, agar pembagian bantuan PKH ini tepat sasaran.

1.3 Batasan Masalah

Pada penelitian ini batasan yang dibahas adalah :

a. Supaya pembagian bantuan PKH ini tepat sasaran kepada penerima bantuan PKH sesuai dengan kriteria yang ditetapkan

b. Sample yang diperoleh dalam penelitian ini didapatkan dari pendamping lapangan program PKH Kecamatan Negerikaton dan karyawan yang bekerja di Dinas Sosial Kabupaten Pesawaran, dan beberapa sumber lain

c. Metode pengumpulan data diperoleh dari wawancara, dokumentasi dan observasi

\subsection{Tujuan Penelitian}

Adapun tujuan penelitian ini adalah :

a. Menerapkan Metode Analytical Hierarcy Process (AHP) dalam penerapan sistem penunjang keputusan bagi masyarakat penerima bantuan $\mathrm{PKH}$

b. Menerapkan penghitungan data menggunakan microsoft excel 2010 sebagai aplikasi pendukung dalam penerapan sistem penunjang keputusan bagi penerima bantuan PKH

c. Pengambilan keputusan dengan menggunakan Metode Analytical Hierarcy Process (AHP) untuk menentukan siapa yang berhak mendapatkan bantuan PKH sesuai dengan kriteria yang telah ditetapkan dan menggunakan software aplikasi pendukung Microsoft Excel 2010 dan di input menggunakan aplikasi web programing untuk menentukan hasil berupa data sebagai sumber yang digunakan untuk proses validasi data akhir penerima bantuan $\mathrm{PKH}$

\subsection{Manfaat Penelitian}

Adapun manfaat dari penelitian ini adalah sebagai berikut :

a. Dengan diterapkan Metode Analytical Hierarcy Process (AHP) diharapkan dapat mempermudah dalam pengambilan keputusan penerima bantuan PKH

b. Dengan menggunakan software aplikasi microsoft excel 2010 dan didukung dengan aplikasi web programing maka diharapkan hasil yang didapatkan dalam pengambilan keputusan semakin valid

c. Hasil dari penelitian ini diharapakn akan dapat mempermudah aparat desa, kaur desa untuk menentukan penerima bantuan $\mathrm{PKH}$, serta meningkatkan kinerja pendamping lapangan program $\mathrm{PKH}$ agar dapat menyalurkan program bantuan $\mathrm{PKH}$ secara tepat sasaran sesuai dengan kriteria yang telah ditetapkan, khususnya bagi Kabupaten Pesawaran.

\section{LANDASAN TEORI}

\subsection{Sistem Pendukung Keputusan (DSS)}

Sistem pendukung keputusan adalah suatu sistem informasi spesifik yang ditujukan untuk membantu manajemen dalam mengambil keputusan yang berkaitan dengan persoalan yang bersifat (Kusumadewi, $2010: 1$ ) :

a. Terstruktur, yaitu : berhubungan dengan persoalan yang telah diketahui sebelumnya dengan penyelesaian standar aturan yang telah ditentukan.

b. Semi terstruktur, yaitu : berhubungan dengan persoalan yang belum diketahui sebelumnya, dengan parameter yang sudah ada. 
c. Tidak terstruktur yaitu : berhubungan dengan persoalan baru yang cukup pelik, karena banyaknya data yang belum diketahui.

2.1.1 Tujuan Sistem Pendukung Keputusan Tujuan sistem pendukung keputusan menurut (Kusrini, M.Kom. : 2010) adalah :

a. Membantu manajer membuat keputusan untuk memecahkan masalah yang sepenuhnya terstruktur dan tidak terstruktur.

b. Mendukung penilaian manajer bukan menggantikannya.

c. Meningkatkan efektivitas pengambilan keputusan manajer terhadapa suatu pemecahan masalah.

Proses pengambilan keputusan seefisien mungkin, juga terdapat manfaat utamanya adalah terdapat hasil keputusan yang lebih baik.

\subsubsection{Tahapan Proses Pengambilan Keputusan}

Tahap - tahap dalam proses pengambilan keputusan yaitu : ( Turban, $2005: 3$ ) :

a. Tahap Penelusuran (Intellegence)

Tahap ini merupakan proses penelusuran, pendeteksian dari lingkup problematika serta proses pengenalan masalah. Data yang diperoleh diproses dan diuji dalam rangka mengidentifikasian masalah.

b. Tahap Perancangan (Design)

Tahap ini merupakan proses menemukan, mengembangkan dan menganalisis tindakan yang mungkin dilakukan. Hal ini meliputi pemahaman terhadap masalah dan menguji solusi yang layak.

c. Tahap Pemilihan (Choice)

Pada tahap ini dibuat suatu keputusan yang nyata dan diambil suatu komitmen untuk mengikuti suatu tindakan tertentu.

d. Tahap Implementasi (Implementation)

Pada tahap ini dibuat suatu solusi yang direkomendasikan dapat bekerja atau implementasi yang diusulkan untuk suatu masalah.

\subsection{Program Keluarga Harapan (PKH)}

Tinjauan tentang program keluarga harapan bersumber dari dokumen-dokumen resmi kementrian RI yang meliputi pedoman PKH tahun : 2015, 2016, 2017.

\subsubsection{Pengertian Program Keluarga Harapan (PKH)}

Berdasasrkan panduan umum program keluarga harapan 2017 adalah : program pemberian bantuan sosial bersyarat kepada keluarga miskin
(KM) yang ditetapkan sebagai keluarga penerima manfaat PKH. Dalam istilah international dikenal dengan nama : Conditional Cash Transfer (CCT).

\subsubsection{Tujuan Program Keluarga Harapan (PKH)} Adapun tujuan dari program bantuan $\mathrm{PKH}$ adalah

a. Meningkatkan tarap hidup keluarga penerima manfaat melalui akses layanan pendidikan, kesehatan dan kesejahteraan sosial.

b. Mengurangi beban pengeluaran dan meningkatkan pendapan keluarga miskin dan rentan.

c. Menciptakan perubahan kemandirian perilaku dan kemandirian keluarga penerima manfaat dalam mengakses layanan kesehatan dan pendidikan serta kesejahteraan sosial.

d. Mengurangi kemiskinan dan kesenjangan antar kelompok pendapatan.

\subsubsection{Penerima Bantuan Program Keluarga} Harapan (PKH)

Adapun kriteria keluarga penerima manfaat yang mendapatkan bantuan PKH pada tahun 2017 ini mengalami 1 peningkatan kriteria, jika pada tahun sebelumnya hanya ada 5 kriteria maka pada tahun 2017 ini terdapat 6 kriteria. Berikut 6 kriteria penerima bantuan PKH serta kewajibanya

Tabel 2.1 Kriteria dan Kewajiban Penerima Bantuan PKH

\begin{tabular}{|c|c|c|c|}
\hline No & KRITERIA & USIA & KEWAJIBAN \\
\hline 1. & $\begin{array}{l}\text { Ibu Hamil/ } \\
\text { Nifas }\end{array}$ & - & $\begin{array}{l}\text { Pemeriksaan kehamilan di faske } \\
\text { sebanyak } 4 \mathrm{x} \text { dalam } 3 \mathrm{x} \text { trimester. }\end{array}$ \\
\hline \multirow[t]{2}{*}{2.} & \multirow[t]{2}{*}{ Bayi } & Usia 0-11 Bulan & $\begin{array}{l}\text { Imunisasi lengkap } \\
\text { pemeriksaan bertat badan } \\
\text { bulan }\end{array}$ \\
\hline & & Usia $6-11$ Bulan & Mendapat suplemen vitamin $\mathrm{A}$ \\
\hline \multirow{3}{*}{3.} & \multirow{3}{*}{ Balita } & Usia 1-5 Tahun & \begin{tabular}{lcr|}
$\begin{array}{l}\text { Imunisasi } \\
\text { pemeriksaan } \\
\text { bulan }\end{array}$ & tambahan & dan \\
tambahan & setiap \\
\end{tabular} \\
\hline & & Usia 5-6 Tahun & $\begin{array}{l}\text { Pemeriksaan berat badan setiap } 1 \\
\text { bulan dan mendapatkan vitamin } \mathrm{A} \\
\text { sebanyak } 2 \mathrm{x} \text { dalam setahum }\end{array}$ \\
\hline & & Usia 6-7 Tahun & Timbang badan di faskes \\
\hline 4. & Anak Sekolah & $\begin{array}{l}\text { Usia 6-21 Tahum } \\
\text { yang behm } \\
\text { menyelesaikan } \\
\text { pendidikan dasar } \\
\text { (SD,SMP, SLTA) }\end{array}$ & \begin{tabular}{lll|} 
& Terdaftar & disekolah \\
& pendidikankesetaraan \\
& Minimal $85 \%$ & kehadiran \\
dikelas &
\end{tabular} \\
\hline 5. & $\begin{array}{l}\text { Penyandang } \\
\text { Disabilitas } \\
\text { Berat }\end{array}$ & - & 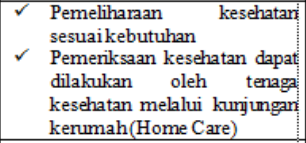 \\
\hline 6. & Lansia Miskin & $70+$ & $\begin{array}{l}\text { Pemeriksaan kesehatan dapat } \\
\text { dilakukan oleh tenaga, } \\
\text { kesehatan atau mengunjung; } \\
\text { puskesmas santum lanjut usia } \\
\text { (jika tersedia) } \\
\text { Mengikuti kegiatan sosial } \\
\text { (Day Care dan Home Care) }\end{array}$ \\
\hline
\end{tabular}

2.2.4 Penyaluran Bantuan Program Keluarga Harapan (PKH) 
Penyaluran bantuan adalah penyaluran dana bantuan penerima PKH yang disalurkan dari rekening pemberi bantuan sosial ke rekening penerima bantuan sosial. Adapun proses penyalurannya adalah sebagai berikut :

a. Bantuan PKH berupa uang

b. Disalurkan 4 tahap dalam 1 tahun

c. Nilai bantuan sama per keluarga (Flat Benefit)

d. Mekanisme tunai dan non tunai

\subsubsection{Mekanisme Pendataan Calon Penerima} $\mathrm{PKH}$

Data penerima $\mathrm{PKH}$ didapatkan Kementrian Sosial berasal dari Badan Pusat Statistik (BPS) yang diperoleh dari hasil pemutakhiran basis data terpadu (PBDT) dan diberikan Ke Dinas Sosial masing-masing Kabupaten kota. Kemudian data tersebut akan di cek/validasi oleh pendamping PKH jika sesuai akan dianggap eligible (berhak mendapatkan bantuan) jika tidak sesuai maka akan dianggap non eligible (tidak mendapatkan bantuan).

2.2.6 Besaran Manfaat dari Banyak Variasi Komponen PKH

Tabel 2.2 Besaran Manfaat dari Banyak Variasi Komponen PKH

\begin{tabular}{|c|l|c|}
\hline No & \multicolumn{1}{|c|}{$\begin{array}{c}\text { Komponen } \\
\text { Bantuan }\end{array}$} & $\begin{array}{c}\text { Indeks Bantuan } \\
\text { (Rp/Tahun/Keluarga }\end{array}$ \\
\hline 1. & KPM Reguler & $1.890 .000,-$ \\
\hline 2. & $\begin{array}{l}\text { KPM Lanjut } \\
\text { Usia }\end{array}$ & $2.000 .000,-$ \\
\hline 3. & $\begin{array}{l}\text { KPM } \\
\text { Penyandang } \\
\text { Disabilitas }\end{array}$ & $\begin{array}{l}\text { KPM Di Papua } \\
\text { dan Papua } \\
\text { Barat }\end{array}$ \\
\hline $4.000 .000,-$ \\
\hline
\end{tabular}

\subsection{Analytical Hierarcy Process (AHP)}

Metode Analytical Hierarcy Process (AHP) merupakan salah satu model pengambilan keputusan untuk membantu kerangka berfikir manusia. Metode ini pertama dikembangkan oleh Thomas L. Saaty pada tahun 70-an. Dasar berfikirnya metode Analytical Hierarcy Process (AHP) adalah proses untuk membentuk skor secara numeric untuk menyusun ranking setiap alternatif keputusan berbasis pada bagaimana sebaiknya alternatif itu dicocokkan dengan kriteria pembuat keputusan.
Analytical Hierarcy Process (AHP) merupakan salah satu metode untuk membantu untuk menyusun suatu prioritas dari berbagai pilihan dengan menggunakan kriteria. Karena sifatnya yang multikriteria, Analytical Hierarcy Process (AHP) cukup banyak digunakan dalam penyusunan prioritas. Sebagai contoh untuk menyususun prioritas penelitian, pihak manajemen lembaga penelitian sering menggunakan beberapa kriteria seperti : dampak penelitian, biaya, kemampuan SDM, dan waktu pelaksanaan.

\subsubsection{Kelebihan Metode Analytical Hierarcy Process (AHP)}

Kelebihan dari model AHP adalah keampuhannya dalam memecahkan masalah multiobjectives dan multikriteria. Fleksibelitasnya tinggi dalam pembuatan hierarki sehingga membuat model AHP ini dapat menangkap beberapa tujuan dan beberapa kriteria sekaligus dalam sebuah model atau dalam sebuah hierarki.

\subsubsection{Kekurangan Metode Analytical Hierarcy Process (AHP)}

Model Analytical Hierarcy Process (AHP) ini juga memiliki beberapa kelemahan. Ketergantungan model ini terhadap input beberapa persepsi seorang ahli akan membuat hasil akhir dari model ini menjadi tidak ada artinya apabila penilaian yg diberikan keliru. Kebanyakan orang bertanya apakah persepsi dari seorang ahli tersebut dapat mewakili kepentingan orang banyak atau tidak.

Keraguan seperti ini disebabkan oleh kenyataan bahwa setiap orang mempunyai persepsi yang berbeda dengan orang lain. Untuk itu harus diberikan batasan tegas dari seorang ahli untuk meyakinkan masyarakat bahwa persepsi si ahli dapat mewakili pendapat masyarakat atau paling tidak sebagian besar masyarakat.

\subsubsection{Langkah-langkah Metode Analytical} Hierarcy Process (AHP)

Menurut (Kusrini, 2007:135), langkah-langkah dalam metode AHP meliputi :

1. Mendifinisikan masalah dan menentukan solusi yang diinginkan

2. Membuat struktur hierarki yang diawali dengan menetapkan tujuan umum, yang merupakan sasaran sistem secara keseluruhan pada level teratas. 
3. Membuat prioritas elemen :

a. Langkah pertama dalam menentukan prioritas elemen adalah membuat perbandingan elemen secara berpasangan sesuai kriteria yang diberikan.

b. Matrik perbandingan berpasangan diisi menggunakan bilangan untuk mempresentasikan kepentingan relatif dari suatu elemen yang lain.

4. Sintesis

Adalah petimbangan-pertimbangan terhadap perbandingan berpasangan, untuk memperoleh keseluruhan prioritas. Langkahlangkah ini adalah :

a. Menjumlahkan nilai dari setiap kolom pada matriks

b. Membagi setiap nilai dari kolom dengan total kolom yang bersangkutan untuk memperoleh normalisasi matriks.

c. Menjumlahkan nilai-nilai dari setiap baris dan membaginya dengan jumlah elemen untuk mendapatkan nilai prioritas.

5. Mengukur konsistensi

Hal-hal yang dilakukan dalam langkah ini adalah :

a. Kalikan setiap nilai pada kolom pertama dengan prioritas relative elemen pertama, dan

nilai pada kolom kedua dengan prioritas relative elemen kedua dan seterusnya.

b. Jumlahkan setiap baris.

c. Hasil penjumlahan tiap baris dibagi prioritas bersangkutan dan hasilnya dijumlahkan.

6. Mencari Nilai Consistency Index (CI)

$\mathrm{CI}=\left(\lambda_{\text {maks }}-\mathrm{n}\right) /(\mathrm{n}-1)$

Keterangan :

$\mathrm{CI}=$ Consistency Indeks

$\lambda_{\text {maks }}=$ eigenvalue maksimum

$\mathrm{n} \quad=$ Banyaknya elemen

7. Mencari nilai Consistency Ratio (CR)

$\mathrm{CR}=\mathrm{CI} / \mathrm{RI}$

Keterangan :

$\mathrm{CR}=$ Consistency Ratio

$\mathrm{CI}=$ Consistency Indeks

RI = Random Indeks

8. Memeriksa konsistensi hirarki, yang diukur adalah rasio konsistensi dengan melihat indeks konsistensi. Jika nilai Consistency Ratio > 0,1 maka penilaian data judgment harus diperbaiki.mengulangi langkah 3, 4 dan 5 untuk seluruh tingkat hirarki. Jika Consistency Ratio < 0,1 maka nilai perbandingan berpasangan pada matriks kriteria yang diberikan konsisten.

\section{METODELOGI PENELITIAN}

3.1 Jenis Penelitian

Penelitian ini bersifat deskriptif, penelitian deskriptif adalah salah satu jenis metode penelitian yang berusaha menggambarkan dan menginterpretasi objek sesuai dengan apa adanya (Best, 1982 : 119).

Penelitian deskriptif memerlukan tindakan yang teliti pada setiap komponennya agar dapat menggambarkan subjek atau objek yang diteliti mendekati kebenarannya. Misalnya : tujuan harus diuraikan secara jelas, permasalahan yang diteliti signifikan, variabel penelitian dapat diukur, teknik sampling harus ditentukan secara hati-hati dan hubungan atau komparasi yang tepat perlu dilakukan untuk mendapatkan gambaran objek atau subjek yang diteliti secara lengkap dan benar.

Keunikan yang ada pada metode penelitian deskriptif antara lain sebagai berikut :

1. Penelitian deskriptif menggunakan kuesioner dan wawancara, seringkali memperoleh responden yang sangat sedikit, akibatnya bias dalam membuat kesimpulan.

2. Penelitian deskriptif yang menggunakan observasi terkadang dalam pengumpulan data tidak memperoleh data yang memadai, untuk itu diperlukan observer yang terlatih dalam observasi, dan jika perlu membuat cheklist lebih dahulu tentang objek yang perlu dilihat sehingga peneliti memperoleh data yang diinginkan.

3. Membutuhkan permasalahan yang harus diidentifikasi dan dirumuskan dengan jelas, agar peneliti tidak mengalami kesulitan dalam menjaring data ketika dilapangan.

\subsection{Tempat dan Waktu Penelitian}

1. Tempat Penelitian

Tempat penelitian ini dilaksanakan di Kabupaten Pesawaran Provinsi Lampung

2. Waktu Penelitian

Waktu penelitian dimulai pada bulan Maret 2018 sampai dengan bulan Maret 2019

\subsection{Teknik Pengumpulan Data}

Teknik pengumpulan data yang dilakukan dalam penelitian ini menggunakan :

1. Wawancara (Interview) 
Merupakan proses untuk menggali informasi secara langsung yang akan dijadikan sebagai sumber data penelitian. Wawancara ini dilakukan dengan informan yang dianggap memiliki representasi informasi yang relevan dengan penelitian yang dilakukan, Misalnya : Pendamping PKH, Operator PKH Kabupaten, Karyawan pada Dinas Sosial.

2. Dokumentasi

Metode ini dilakukan dengan cara mencari data mengenai catatan-catatan, dokumendokumen, transkrip, buku-buku, surat kabar, majalah dan lain sebagainya yang diharapkan dari data tersebut dapat menjadi pendukung dalam penelitian ini terutama tentang teori, pendapat, serta pemikiran terkait dengan dampak kebijakan terhadap kebijakan Program Keluarga Harapan terhadap masyarakat penerima bantuan.

3. Observasi

Kegiatan ini adalah suatu aktivitas terhadap suatu proses atau objek dengan merasakan dan memahami pengetahuan dari sebuah fenomena berdasarkan pengetahuan dan gagasan yang sudah diketahui sebelumnya, untuk mendapatkan informasi yang dibutuhkan dalam melakukan penelitian. Misalnya : mengamati langsung pelaksanaan program PKH.

3.4 Teknik Analisis Data

Pengerjaan analisis data dalam penelitian ini akan menggunakan Metode Analytical Hierarcy Process (AHP) dan pengolahan data (pembobotan kriteria) akan menggunakan Microsoft Excel 2010. Kemudian dilanjutkan dengan menggunakan program aplikasi web programing dan hasil akhir yang didapatkan berupa data sebagai sumber yang digunakan untuk proses validasi data akhir penerima bantuan PKH yang didapat dari Kementrian Sosial yang Bersumber dari Badan Pusat Statistik oleh pendamping $\mathrm{PKH}$.

\subsection{Tahapan Perancangan}

Tahapan Perancangan dalam penelitian ini akan dibagi menjadi dua yaitu perancangan kerja dan perancangan proses.

\subsubsection{Perancangan Kerja}

Yang tertuang dalam alur langkah penelitian seperti gambar berikut :

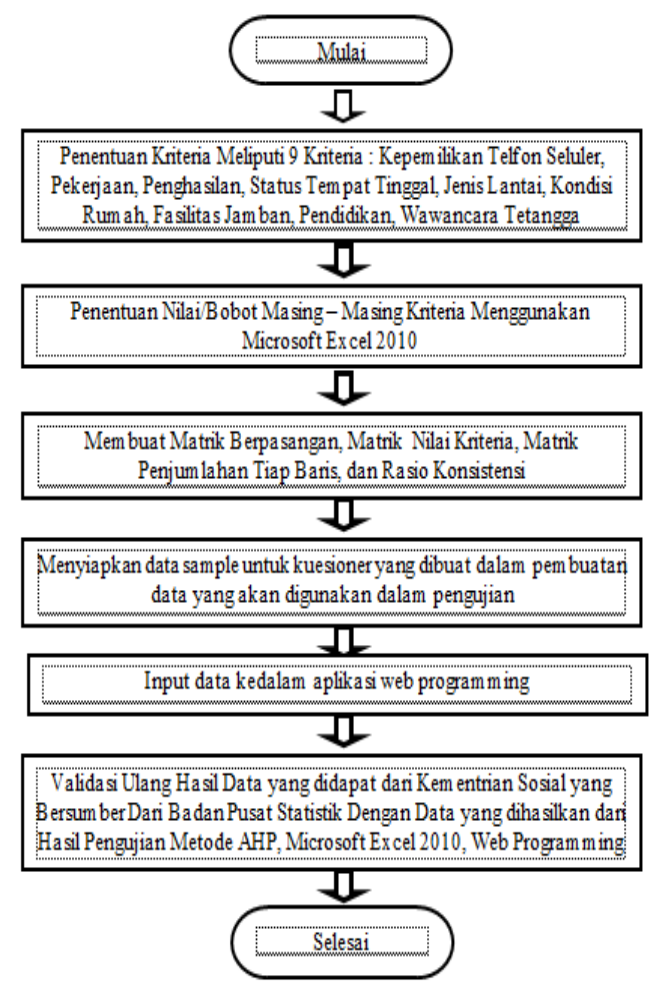

Gambar 3.1 Diagram Alur Langkah Penelitian

\subsubsection{Perancangan Proses}

Tertuang dalam struktur hierarki seperti pada gambar berikut :

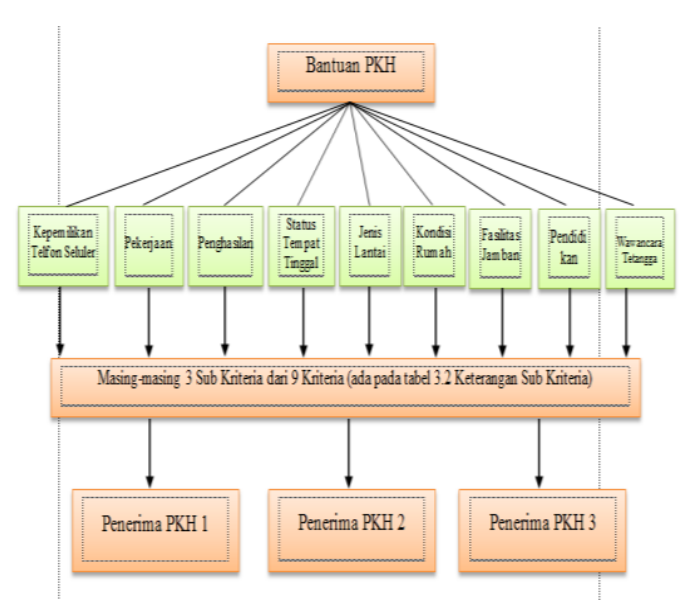

Gambar 3.2 Struktur Hierarki Kriteria Penerima PKH

\subsubsection{Keterangan Proses}

Tabel 3.1 Keterangan Kriteria Penerima PKH 


\begin{tabular}{|c|l|}
\hline Kriteria & \multicolumn{1}{|c|}{ Keterangan } \\
\hline K1 & Kepemilikan Telfon Seluler \\
\hline K2 & Pekerjaan \\
\hline K3 & Penghasilan \\
\hline K4 & Status Tempat Tinggal \\
\hline K5 & Jenis Lantai \\
\hline K6 & Kondisi Rumah \\
\hline K7 & Fasilitas Jamban \\
\hline K8 & Pendidikan \\
\hline K9 & Wawancara Tetangga \\
\hline
\end{tabular}

\section{Tabel 3.2 Keterangan Sub Kriteria} Penerima PKH

\begin{tabular}{|c|c|c|}
\hline \multirow{4}{*}{ Kl } & Kepemilikan Telfon Seluler & Nilai \\
\hline & Tidak Punya & 5 \\
\hline & Non Smartphone & 3 \\
\hline & Smartphone & 1 \\
\hline \multirow{4}{*}{$\mathrm{K} 2$} & Pekerjaan & Nilai \\
\hline & Tidak Punya Pekerjaan & 5 \\
\hline & Tidak Pasti & 3 \\
\hline & Punya & 1 \\
\hline \multirow{4}{*}{ K3 } & Penghasilan & Nilai \\
\hline & $<500.000$ & 5 \\
\hline & $500.000-1.500 .000$ & 3 \\
\hline & $>1.500 .000$ & 1 \\
\hline \multirow{4}{*}{ K4 } & Status Tempat Tinggal & Nilai \\
\hline & Numpang & 5 \\
\hline & Sewa & 3 \\
\hline & Milik Sendin & 1 \\
\hline \multirow{4}{*}{ K5 } & Jenis Lantai & Nilai \\
\hline & Lantai Tanah & 5 \\
\hline & Lantai Semen & 3 \\
\hline & Lantai Keramik & 1 \\
\hline \multirow{4}{*}{ K6 } & Kondisi Rumah & Nilai \\
\hline & Bambu & 5 \\
\hline & Papan & 3 \\
\hline & Semen & 1 \\
\hline \multirow{4}{*}{ K7 } & Fasilitas Jamban & Nilai \\
\hline & Tidak Punya & 5 \\
\hline & Biasa & 3 \\
\hline & Bagus & 1 \\
\hline \multirow{4}{*}{ K8 } & Pendidikan & Nilai \\
\hline & Tidak Sekolah & 5 \\
\hline & SD, SLTP, SMA & 3 \\
\hline & Perguruan Tinggi & 1 \\
\hline \multirow{4}{*}{ K9 } & Wawancara Tetangga & Nilai \\
\hline & Sangat Layak & 5 \\
\hline & Layak & 3 \\
\hline & Tidak Layak & 1 \\
\hline
\end{tabular}

\subsection{Instrumen Penelitian}

Instrumen yang digunakan dalam penelitian ini adalah berupa Kuesioner yang dirancang sebagai sarana dalam pengambilan data penelitian

Berikut ini gambar kuesioner yang dirancang

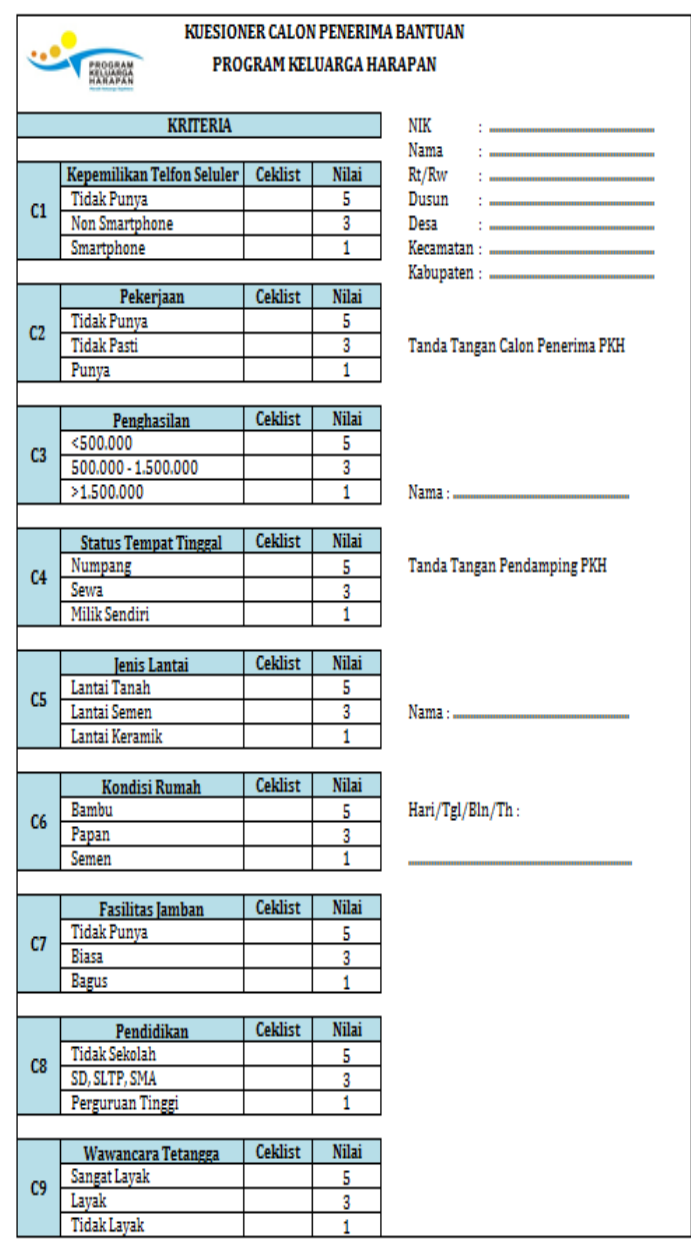

Gambar 3.3 Kuesioner Calon Penerima PKH

4. HASIL

4.2 Hasil Penelitian

Berdasarkan penelitian yang dilakukan dan wawancara bersama pendamping $\mathrm{PKH}$, maka lebih tepat harus ditentukan jenis kriteria yang tepat untuk proses penentuan penerima bantuan program keluarga harapam. Dan didapatkan 9 kriteria yang dipandang layak untuk dijadikan tolak ukur, selanjutnya kriteria tersebut akan dihitung berdasarkan langkah metode AHP. Berikut 9 kriteria yang sudah ditentukan tertuang dalam tabel 4.1.

Tabel 4.1 Kriteria Penerima Bantuan PKH

\begin{tabular}{|c|l|c|l|c|l|}
\hline NO & \multicolumn{1}{|c|}{ KRITERIA } & NO & \multicolumn{1}{|c|}{ KRITERIA } & NO & KRITERIA \\
\hline 1. & $\begin{array}{l}\text { Kepemilikan Telfon } \\
\text { Seluler }\end{array}$ & 4. & $\begin{array}{l}\text { Status Tempat } \\
\text { Tinggal }\end{array}$ & 7. & $\begin{array}{l}\text { Fasilitas } \\
\text { Jamban }\end{array}$ \\
\hline 2. & Pekerjaan & 5. & Jenis Lantai & 8. & Pendidikan \\
\hline 3. & Penghasilan & 6. & Kondisi Rumah & 9. & $\begin{array}{l}\text { Wawancara } \\
\text { Tetangga }\end{array}$ \\
\hline
\end{tabular}


Dan akan diturunkan kedalam sub kriteria dengan memberikan pembobotan pada setiap sub kriteria seperti pada tabel 4.2.

Tabel 4.2 SubKriteria Penerima Bantuan PKH

\begin{tabular}{|c|c|c|}
\hline \multirow{4}{*}{ K1 } & Kepemilikan Telfon Seluler & Nilai \\
\hline & Tidak Punya & 5 \\
\hline & Non Smartphone & 3 \\
\hline & Smartphone & 1 \\
\hline \multirow{4}{*}{ K2 } & Pekerjaan & Nilai \\
\hline & Tidak Punya Pekerjaan & 5 \\
\hline & Tidak Pasti & 3 \\
\hline & Punya & 1 \\
\hline \multirow{4}{*}{ Кз } & Penghasilan & Nilai \\
\hline & $<500.000$ & 5 \\
\hline & $500.000-1.500 .000$ & 3 \\
\hline & $>1.500 .000$ & 1 \\
\hline \multirow{4}{*}{ K4 } & Status Tempat Tinggal & Nilai \\
\hline & Numpang & 5 \\
\hline & Sewa & 3 \\
\hline & Milik Sendiri & 1 \\
\hline \multirow{4}{*}{ K5 } & Jenis Lantai & Nilai \\
\hline & Lantai Tanah & 5 \\
\hline & Lantai Semen & 3 \\
\hline & Lantai Keramik & 1 \\
\hline \multirow{4}{*}{ K6 } & Kondisi Rumah & Nilai \\
\hline & Bambu & 5 \\
\hline & Papan & 3 \\
\hline & Semen & 1 \\
\hline \multirow{4}{*}{ K7 } & Fasilitas Jamban & Nilai \\
\hline & Tidak Punya & 5 \\
\hline & Biasa & 3 \\
\hline & Bagus & 1 \\
\hline \multirow{4}{*}{ K8 } & Pendidikan & Nilai \\
\hline & Tidak Sekolah & 5 \\
\hline & SD, SLTP, SMA & 3 \\
\hline & Perguruan Tinggi & 1 \\
\hline \multirow{4}{*}{ K9 } & Wawancara Tetangga & Nilai \\
\hline & Sangat Layak & 5 \\
\hline & Layak & 3 \\
\hline & Tidak Layak & 1 \\
\hline
\end{tabular}

Berdasarkan kriteria dan subkriteria tersebut akan diujicoba matrik perbandingan berpasangan dengan menggunakan metode AHP.

4.2 Perhitungan Menggunakan Metode Analytic Hierarchy Process (AHP)

Langkah-langkah pembuatan pada setiap matriks menggunakan dasar Tabel Skala Saaty seperti pada tabel 4.3 sebagai berikut :

Tabel 4.3 Skala saaty (Skala Perbandingan Pasangan)

\begin{tabular}{|c|c|c|}
\hline \begin{tabular}{|c|} 
Intensitas \\
Kepentingan \\
\end{tabular} & Keterangan & Penjelasan \\
\hline 1 & $\begin{array}{l}\text { Kedua elemen sama } \\
\text { pentingnya }\end{array}$ & $\begin{array}{l}\text { Dua elemen mempunyai } \\
\text { pengaruh yang sama besar } \\
\text { terhadap tujuan }\end{array}$ \\
\hline 3 & $\begin{array}{l}\text { Elemen yang satu sedikit lebih } \\
\text { penting dari pada elemen } \\
\text { yang lainnya }\end{array}$ & $\begin{array}{l}\text { Pengalaman dan penilaian } \\
\text { sedikit menyokong satu elemen } \\
\text { dibandingkan elemen lainnya }\end{array}$ \\
\hline 5 & $\begin{array}{l}\text { Elemen yang satu lebih } \\
\text { penting dari pada elemen } \\
\text { yang lainnya }\end{array}$ & $\begin{array}{l}\text { Pengalaman dan penilaian } \\
\text { sangat kuat menyokong sat } \\
\text { elemen dibandingkan elemen } \\
\text { lainnya }\end{array}$ \\
\hline 7 & $\begin{array}{l}\text { Satu elemen jelas lebih } \\
\text { penting dari pada elemen } \\
\text { lainnya }\end{array}$ & $\begin{array}{l}\begin{array}{l}\text { Satu elemen yang kuat } \\
\text { dikosongkan dominan terlihat } \\
\text { dalam praktek }\end{array} \\
\end{array}$ \\
\hline 9 & $\begin{array}{l}\text { Satu elemen mutlak penting } \\
\text { dari pada elemen lainnya }\end{array}$ & $\begin{array}{l}\text { Bukti yang mendukung elenien } \\
\text { yang satu terhadap elemen lain } \\
\text { memiliki tingkat penegasan } \\
\text { tertinggi yang mungkin } \\
\text { menguatkan }\end{array}$ \\
\hline $2,4,6,8$ & $\begin{array}{l}\text { Nilai ragu-ragu antara dua } \\
\text { nilai yang berdekatan }\end{array}$ & $\begin{array}{l}\text { Nilai ini diberikan bila ada cua } \\
\text { kompromi diantara dua pilihan }\end{array}$ \\
\hline Kebalikan & $\begin{array}{l}\text { Jika untuk aktivitas I mend } \\
\text { aktivitas j, maka j mempu }\end{array}$ & $\begin{array}{l}\text { satu angka disbanding dengan } \\
\text { ilai kebalikannya dibanding } \\
\text { in } \mathrm{i}\end{array}$ \\
\hline
\end{tabular}

Dan untuk nilai Inconsistenci Ratio menggunakan tabel IR pada tabel 4.4 sebagai berikut :

Tabel 4.4 Tabel IR (Inconsistency Ratio)

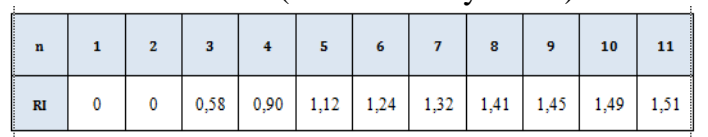

\subsection{Menentukan Prioritas Kriteria}

4.3.1 Membuat Matriks Perbandingan Berpasangan (Ps)

Pada tahap ini dilakukan penilaian perbandingan antara satu kriteria dengan kriteria yang lain. Panduan pemberian nilai perbandingan pasangan kriteria bisa dilihat pada tabel 4.3 Skala Perbandingan Berpasangan. Berikut ini tabel perbandingan berpasangan yang tercipta setelah konsultasi dengan pendamping $\mathrm{PKH}$ untuk menentukan bobot masing-masing kriteria untuk dijadikan sebagai acuan dalam pembuatan matriks perbandingan berpasangan seperti pada tabel 4.5.

Tabel 4.5 Matriks Perbandingan Berpasangan (Ps)

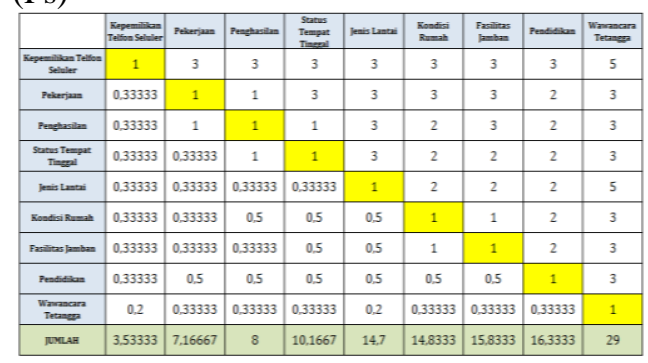

4.3.2 Matriks Nilai kriteria dinormalkan (Mn)

Matriks ini diperoleh dengan menormalkan seluruh nilai matriks dengan rumus :

$\mathbf{M n}=\mathbf{P s} / \mathbf{J k}$ 
Keterangan : Mn = Matriks Nilai kriteria dinormalkan

$$
\begin{gathered}
\text { Ps }=\text { Matriks Perbandingan } \\
\text { Berpasangan } \\
\text { Jk }=\text { Jumlah Kolom }
\end{gathered}
$$

\begin{tabular}{|c|c|c|c|c|c|c|c|c|c|c|c|}
\hline & II & I & B & IH & IS & If & వ & I & III & $\begin{array}{c}\text { Itah aris } \\
\text { (it) }\end{array}$ & Rinits $(\mathbb{P})$ \\
\hline II & 10301008 & Q1460145. & 0375 & |050:1696| & |024:6633 & amants: & 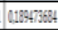 & 104683469 & 1072:13793 & 230506 & (1580175: \\
\hline 2 & 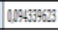 & 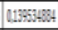 & 4.15 & 10551:156 & 0204:1633 & and-19: & 0.186473804 & 0.124898 & 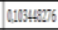 & 1.65600 & 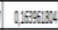 \\
\hline$\pi$ & |004415623 & 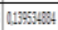 & 0.15 & 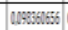 & 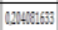 & (1345:16: & 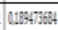 & a124-989 & a104W06 & 12131585 & U13E13H \\
\hline It & 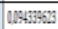 & Co4561168 & 0.15 & |cosersobs & 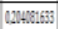 & 1.345145: & 010651576 & U1214\%9 & anaHerb & $1553: 8066$ & 0 \\
\hline IJ & 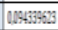 & OH:551658 & aytestes? & 7 asioumas & acsurzu1 & (1345:15: & $10165150 \%$ & 102489 & |ar74:1399 & GESOLE & 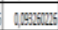 \\
\hline If & QDS4:35623 & CL4561168 & 0.665 & Whasuss & WBAH:3655 & .66-1519 & 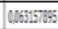 & 1.124989 & anaHED6 & 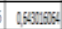 & unvere \\
\hline$\pi$ & |004:35623 & O4551658 & |c4sts660 & 7 Oatias: & U134:3655 & w66t:575 & wo6silin: & 11048ss & Q1014506 & 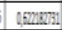 & WE:HE \\
\hline II & OSA413623 & assitith & 06025 & WHFins: & 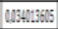 & 108390786 & 001515849 & wobi21.99 & Q1034HOD & 4.59556 & Q \\
\hline II & U1560137- & 104561688 & orisemb & 1 aszowows & 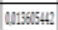 & umphig1 & amicks: & anostot & 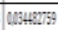 & $0.25 s=$ & 0,0200 \\
\hline
\end{tabular}

Tabel 4.6 Matriks Nilai Kriteria

Perhitungan Jumlah baris ( $\mathrm{Jb}$ ) diperoleh dari : K1 $+\mathrm{K} 2$ + K3 s.d K9

Prioritas (P) diperoleh dari : Jumlah baris (Jb) dibagi Jumlah Kriteria

Yaitu : 2,323595257/9 = 0,258177251 dst ...

4.3.3 Perkalian Matrik Perbandingan Dengan Matrik Prioritas

Matriks ini dibuat dengan mengalikan nilai prioritas pada tabel 4.6 dengan matriks perbandingan berpasangan pada tabel 4.5

\begin{tabular}{|c|c|c|c|c|c|c|c|c|c|c|}
\hline & K1 & 12 & $\mathrm{~B}$ & Bf & $\mathrm{KS}$ & $\mathbb{K} 6$ & 17 & $\mathrm{~KB}$ & E9 & $\begin{array}{c}\text { Jumah baris } \\
\text { (bb) }\end{array}$ \\
\hline K1 & 0.25817751 & Q441955:12 & 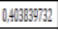 & 035577948 & 029906079 & 02214396808 & 020139421H & 0199001929 & 0161083255 & 251798500 \\
\hline $\mathrm{N} 2$ & 0.0060501904 & 0169361044 & 0.13661324 & 0353177948 & 027990679 & 0224736808 & 0.207394214 & 0.1994675 & 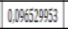 & 1,654010385 \\
\hline $\mathrm{BB}$ & 0.086650104 & 01693960104 & 0.13461324 & 0117159983 & 0279060679 & 0.1499459 & 0.2013942H & 011946/195 & 00065692933 & 13946000 \\
\hline $\mathbb{B} 4$ & Q008065004 & Q053653935 & 0.13461324 & 0117159783 & 027990679 & 0.1489255 & 01.136628089 & $0.19467 \% 5$ & 0094659433 & 116998985 \\
\hline 15 & Q0086059504 & 0054639355 & 0044871061. & 0.03986584 & 0093560226 & 01.1289459 & Q1.138668289 & 0.1994675 & 01016083255 & 0.899916588 \\
\hline $\mathrm{N} 6$ & 0.006615904 & 0054539355 & 0.66736522 & 015860961. & ONG6000113 & anritw220 & Q0069:314.15 & 0.1994765 & 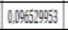 & 06703034036 \\
\hline II & Q0086069004 & 005K539355 & OxH4871081 & 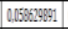 & ON46050113 & an'45220 & 0.069:313415 & 011946475 & 0006569533 & 0,67804965 \\
\hline 188 & 0.008650504 & Q08199012 & 0,6673662 & Q103569091 & ONG6601113 & 00257213115 & 0.0355650707 & Q1599473991 & 0.096529533 & 0,5673987 \\
\hline Bg & 00051626355 & 0054635955 & 0.44871061 & 0.0390654 & 0001855045 & 0.002805 .511 & Q0.023433005 & 000999:132 & 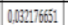 & 0.30916104 \\
\hline
\end{tabular}

Tabel 4.7 Perkalian Matriks Perbandingan Dengan Matriks Prioritas

4.3.4 Perhitungan Rasio Konsistensi

Perhitungan ini digunakan untuk memastikan bahwa perhitungan nilai rasio konsistensi (CR) $<=0,1$.

"jika ternyata nilai CR lebih besar dari 0,1 maka nilai matriks perbandingan berpasangan harus diperbaiki."

Tabel 4.8 Perhitungan Rasio Konsistensi

\begin{tabular}{|c|l|c|c|c|}
\hline Kriteria & & Jumlah Baris & Prioritas (P) & Hasil \\
\hline (b) & Kepemilikan Telfon Seluler & 2,547998801 & 0,258177251 & 2,806176051 \\
\hline K2 & Pekerjaan & 1,654403838 & 0,163961804 & 1.818365642 \\
\hline K3 & Penghasilan & 1,348438043 & 0.134613244 & 1.483051287 \\
\hline K4 & Status Tempat Tinggal & 1,169998759 & 0,117259783 & 1,287258542 \\
\hline K5 & Jenis Lantal & 0,879916258 & 0,093260226 & 0.973176484 \\
\hline K6 & Kondisi Rumah & 0,670334036 & 0,071446229 & 0.741780266 \\
\hline K7 & Fasilitas Jamban & 0,647898496 & 0,069131415 & 0.71702991 \\
\hline K8 & Pendidikan & 0,567398784 & 0,059973397 & 0.627372182 \\
\hline K9 & Wawancara Tetangga & 0,307926104 & 0.032176651 & 0.340102755 \\
\hline \multicolumn{4}{|c|}{ JUMLAH } \\
\hline
\end{tabular}

Kolom Jumlah baris $(\mathrm{Jb})$ diperoleh atau sama dengan Kolom jumlah baris pada tabel 4.7 sedangkan Kolom Prioritas (P) diperoleh atau sama dengan kolom Prioritas pada tabel 4.6 kemudian dijumlahkan $(\mathbf{J b}+\mathbf{P})=\mathbf{J u m l a h}$.

Dari tabel 4.6 diperoleh Jumlah $=10.79431312$ $\mathbf{n}=$ Jumlah Kriteria $=9$ $\lambda_{\text {maksimum }}=\mathrm{Jumlah} / \mathrm{n}$ $=1,1993681$

\section{CI $\left(\lambda_{\text {maksimum }}-\mathbf{n}\right) /(\mathbf{n}-\mathbf{1})=$ - $\mathbf{7 , 8 0 0 6 3 2 / 8}=\mathbf{- 0 , 9 7 5 0 7 9}$ \\ $\mathrm{CR}=\mathrm{CI} / \mathrm{IR}=\mathbf{- 0 , 6 7 2 4 6 8}$}

Hasil : $\mathbf{C R}<\mathbf{0 , 1}$, Maka rasio konsistensi dari perhitungan dapat diterima

\subsection{Menentukan Prioritas SubKriteria}

Perhitungan subkriteria dilakukan terhadap subsub dari semua kriteria. Pada studi kasus yang diambil peneliti terdapat 9 kriteria dan masingmasing terdapat 3 subkriteria yang harus diuji Konsistensi Rasionya (CR). Berikut langkahlangkah perhitungan subkriteria :

4.4.1 Menghitung subkriteria (K1) Kepemilikan Telepon Seluler

a. Membuat Matriks Perbandingan Berpasangan K1

Tabel 4.8 Matriks Perbandingan Berpasangan K1

\begin{tabular}{|l|c|c|c|}
\hline & Tidak Punya & $\begin{array}{c}\text { Non } \\
\text { Smartphone }\end{array}$ & Smartphone \\
\hline Tidak Punya & 1 & 3 & 5 \\
\hline Non Smartphone & 0,33333333 & 1 & 3 \\
\hline Smartphone & 0,2 & 0,33333333 & 1 \\
\hline JUMLAH & 1,53333333 & 4,33333333 & 9 \\
\hline
\end{tabular}

b. Membuat Matriks Nilai Kriteria K1 Tabel 4.9 Matriks Nilai Kriteria K1

\begin{tabular}{|l|c|c|c|c|c|}
\hline & $\begin{array}{c}\text { Tidak } \\
\text { Punya }\end{array}$ & $\begin{array}{c}\text { Non } \\
\text { Smartphone }\end{array}$ & Smartphone & $\begin{array}{c}\text { Jumlah Baris } \\
\text { (Jb) }\end{array}$ & $\begin{array}{c}\text { Prioritas } \\
\text { (P) }\end{array}$ \\
\hline Tidak Punya & 0,65217391 & 0,69230769 & 0,55555556 & 1,90003716 & 0,63334572 \\
\hline Non Smartphone & 0,2173913 & 0,23076923 & 0,33333333 & 0,78149387 & 0,26049796 \\
\hline Smartphone & 0,13043478 & 0,07692308 & 0,11111111 & 0,31846897 & 0,10615632 \\
\hline
\end{tabular}

c. Perkalian Matriks Perbandingan dengan matriks Prioritas

Tabel 4.10 Matriks Perbandingan dengan matriks Prioritas K1

\begin{tabular}{|l|c|c|c|c|}
\hline & $\begin{array}{c}\text { Tidak } \\
\text { Punya }\end{array}$ & $\begin{array}{c}\text { Non } \\
\text { Smartphone }\end{array}$ & Smartphone & $\begin{array}{c}\text { Jumlah } \\
\text { Baris (Jb) }\end{array}$ \\
\hline Tidak Punya & 0,63334572 & 0,78149387 & 0,53078162 & 1,94562121 \\
\hline Non Smartphone & 0,21111524 & 0,26049796 & 0,31846897 & 0,79008217 \\
\hline Smartphone & 0,12666914 & 0,08683265 & 0,10615632 & 0,31965812 \\
\hline
\end{tabular}

d. Penghitungan Rasio Konsistensi

Tabel 4.11 Matriks Rasio Konsistensi K1 


\begin{tabular}{|l|c|c|c|}
\hline & Jumlah Baris (Jb) & Prioritas (P) & Hasil \\
\hline Tidak Punya & 1,94562121 & 0,63334572 & 2,57896693 \\
\hline Non Smartphone & 0,79008217 & 0,26049796 & 1,05058012 \\
\hline Smartphone & 0,31965812 & 0,10615632 & 0,42581444 \\
\hline \multicolumn{3}{|c|}{ Jumlah } & 4,0553615 \\
\hline
\end{tabular}

$$
\begin{array}{cl}
\text { Jumlah }=\text { 4,0553615 } & \\
\mathbf{n}=\text { Jumlah Kriteria } & =\mathbf{3} \\
& \lambda_{\text {maksimum }}=\text { Jumlah } / \mathbf{n} \\
& =\mathbf{1 , 3 5 1 7 8 7 1 6 4} \\
\text { CI } & \left(\lambda_{\text {maksimum }} \quad-\mathbf{n}\right) /(\mathbf{n}-\mathbf{1})=- \\
\mathbf{1 , 6 4 8 2 1 / 2} & =\mathbf{- 0 , 8 2 4 1 0 6 4 1 8} \\
\text { CR } & =\mathbf{C I} / \mathbf{I R}=\mathbf{- 1 , 4 2 0 8 7 3 1 3 4}
\end{array}
$$

Hasil : $\mathbf{C R}<\mathbf{0 , 1}$, Maka rasio konsistensi dari perhitungan dapat diterima

Pada 8 subkriteria yang lain juga sama cara perhitungan rasio konsistensinya.

\subsection{Pengujian Menggunakan Sample Data Penerima PKH}

Sebelum pengujian dilaksanakan maka terlebih dahulu harus mengisi kuesioner yang sudah disiapkan. Dalam penelitian kali ini peneliti menggunakan 45 data sample untuk uji coba perhitungan menggunakan Microsoft Excel 2010 dan akan dilanjutkan dengan program aplikasi yang dibuat menggunakan Web Programming.

\subsubsection{Data sample sesuai dengan nilai kuesioner yang diisi}

Penerima bantuan program keluarga harapan desa Roworejo, Kecamatan Negerikaton Kabupaten Pesawaran yang dibuat sebagai sample dalam pengisian kuesioner yang hasilnya tertuang dalam tabel 4.12.

Tabel 4.12 Data Sampel Penerima Bantuan Program $\mathrm{PKH}$

\begin{tabular}{|c|l|c|c|c|c|c|c|c|c|c|}
\hline \multirow{2}{*}{ N0 } & \multirow{2}{*}{$\begin{array}{c}\text { NAMA CAL0N } \\
\text { PENERIMA }\end{array}$} & \multicolumn{9}{|c|}{ KRITERIA } \\
\cline { 3 - 12 } & & K1 & K2 & K3 & K4 & K5 & K6 & K7 & K8 & K9 \\
\hline 1 & Munta Siroh & 5 & 1 & 3 & 1 & 1 & 1 & 3 & 3 & 3 \\
\hline 2 & Kutsiah & 3 & 1 & 3 & 1 & 1 & 1 & 3 & 3 & 3 \\
\hline 3 & Gutri Trirahayu Ningsih & 1 & 3 & 3 & 1 & 3 & 1 & 3 & 3 & 3 \\
\hline 4 & Katimah & 1 & 3 & 5 & 1 & 3 & 1 & 3 & 3 & 3 \\
\hline 5 & Siti Nuriyah & 3 & 3 & 5 & 1 & 1 & 1 & 3 & 3 & 1 \\
\hline
\end{tabular}

\section{PENUTUP}

\subsection{KESIMPULAN}

Berdasarkan hasil penelitian pada Sistem Pengambilan Keputusan Calon Penerima
Bantuan Program Keluarga Harapan Menggunakan Metode Analytical Hierarcy Process (AHP) (Studi Kasus Kabupaten Pesawaran), maka dapat diambil kesimpulan :

1. Pada proses sistem pengambilan keputusan calon penerima bantuan PKH ini diperlukan penentuan kriteria serta bobot yang tepat yang dilakukan berdasarkan wawancara bersama antara peneliti, petugas pendamping $\mathrm{PKH}$ dan beberapa karyawan di Dinas PKH yang digunakan sebagai acuan dalam proses perhitungan menggunakan metode AHP.

2. Hasil dari perhitungan yang dilakukan menggunakan aplikasi Microsoft Excel 2010 dapat menghasilkan data yang diinginkan yaitu perangkingan data calon penerima bantuan PKH yang apabila dibutuhkan seleksi misalnya dari 200 nama calon penerima akan diambil 120 calon penerima, maka dapat diputuskan 120 rangking teratas adalah calon yang dipastikan lolos seleksi calon penerima bantuan PKH.

3. Perhitungan menggunakan Aplikasi berbasis Web akan sangat memudahkan bagi pendamping $\mathrm{PKH}$ untuk melakukan proses seleksi, mengingat seleksi bagi calon penerima bantuan PKH yang dilakukan oleh petugas pendamping $\mathrm{PKH}$ hanya dilakukan selama 2 hari, sehingga program aplikasi berbasis web ini akan sangat membantu petugas pendamping $\mathrm{PKH}$ dalam proses validasi ulang bagi calon penerima bantuan PKH. [6]

4. Perhitungan dengan menggunakan metode AHP yang dilakukan menggunakan Microsoft Excel 2010 lebih lambat dibandingkan dengan aplikasi berbasis Web, karena rumus yang digunakan akan melalui proses yang berulang-ulang namun pada aplikasi berbasis Web sudah dibuat pada coding program.

\subsection{SARAN}

Saran peneliti pada penelitian ini adalah sebagai berikut :

1. Bagi petugas pendamping $\mathrm{PKH}$ agar dapat menggunakan kuesioner yang ada untuk memaksimalkan proses seleksi calon penerima bantuan PKH dengan mewajibkan mengisi kuesioner di Kantor Balai Desa dengan didampingi kaur desa, kepala desa, dan petugas pendamping $\mathrm{PKH}$, sehingga proses pengisian benar-benar dilakukan oleh calon penerima bantuan PKH sehingga data yang didapatkan benar-benar valid. 
2. Agar program aplikasi ini dapat digunakan untuk memudahkan petugas pendamping $\mathrm{PKH}$ dalam proses validasi ulang calon penerima bantuan $\mathrm{PKH}$.

3. Bagi peneliti selanjutnya untuk dapat menyempurnakan program aplikasi yang dibuat sehingga aplikasi ini bisa digunakan secara online, dan semua petugas pendamping $\mathrm{PKH}$ akan dengan mudah menggunakannya, dan database seleksi calon penerima bantuan $\mathrm{PKH}$ bisa terpusat dalam satu sistem.

\section{DAFTAR PUSTAKA}

[1] Badan Pusat Statistik 2017, Profil Kemiskinan di Indonesia September 2017, Jakarta. Hermawanti Marhaeni, M.Sc.

[2] Direktorat Jenderal Perlindungan dan Jaminan Sosial 2017, Kebijakan Pelaksanaan Program Keluarga Harapan Tahun 2017, Padang.

[3] Badan Pusat Statistik 2017, Kabupaten Pesawaran Dalam Angka 2017, Gedong Tataan, Wintarti Dyah indriani, S.E.

[4] Nur Aminudin, Ida Ayu Puspita Sari "Sistem Pendukung Keputusan (DSS) Penerima Bantuan Program Keluarga Harapan (PKH) Pada Desa Bangun Rejo Kec. Punduh Pidada Pesawaran Dengan Menggunakan Metode Analytical Hierarcy Process (AHP)".

[5] Rofiqoh Hasanah, Ristu Saptono, Rini Anggrainiingsih "Decision Support System Validation Recipient Program Keluarga Harapan (PKH) in Wonosari Distric Using AHP-TOPSIS Method. Jurnal Ilmiah Teknologi dan Informasi Vol.5, No.2, Desember 2016.

[6] Ardhy, Ferly. "Sistem Informasi Geografis Penyedia Jasa Rumah Kos Berbasis Website (Studi Kasus: Wilayah Kotabumi Lampung Utara)." SIMADA (Jurnal Sistem Informasi dan Manajemen Basis Data) 1.1 (2018): 41-50. 